\title{
Cultura contemporânea e narrativas jornalísticas: a construção da diferença nas reportagens de Nana Queiroz e Fabiana Moraes
}

\author{
Fernanda Salvo \\ Doutora; Pontifícia Universidade Católica de Minas Gerais, Belo Horizonte, MG, Brasil \\ fernandasalvo@hotmail.com
}

\section{Resumo}

Este artigo reflete sobre os modos de abordagem e os recursos expressivos utilizados por Nana Queiroz, em Presos que menstruam, e por Fabiana Moraes, em O nascimento de Joicy, para conferir visibilidade às vidas anônimas das quais resolveram se aproximar. Compreender como tais narrativas produzem sentidos sobre a diferença, compartilhados na arena de disputas simbólicas da cultura contemporânea, é o objetivo que nos guia. Em suas narrativas, Queiroz e Moraes esboçam gesto parecido: evitam os modos codificados de relatar a alteridade, preferindo construir entradas pelos espaços de invenção dos sujeitos narrados - inscrevendo suas falas, experiências e os modos singulares que afastam as concepções generalizantes. Amparadas no "eu" para produzir os relatos, Queiroz e Moraes apresentam retórica testemunhal e reflexiva, numa escrita pontuada pela sua subjetividade e a de seus personagens.

\section{Palavras-chave}

Cultura contemporânea. Narrativas jornalísticas. Alteridade. Disputas simbólicas. Cotidiano.

\section{Introdução}

Neste artigo buscamos descrever como os componentes de duas reportagens brasileiras contemporâneas - Presos que menstruam (2015), de Nana Queiroz, e $O$ nascimento de Joicy (2015), de Fabiana Moraes, entram em fricção com as forças heterogêneas do mundo social, tensionando representações sedimentadas sobre a diferença - como aquelas comumente exibidas pela mídia hegemônica. 0 esforço é identificar os 
caminhos percorridos por Nana Queiroz e Fabiana Moraes na realização das reportagens que trazem para o campo discursivo da mídia questões que afligem a sociedade atual - como suas divisões simbólicas e a presença (quase sempre indesejada) da diferença.

Em Presos que menstruam, Nana Queiroz aborda a situação do sistema carcerário brasileiro, revelando sua face menos visível: a vida de mulheres presas, tratadas como homens na cadeia. A reportagem apresenta relatos protagonizados por sete presidiárias, que se somam às experiências de diversas detentas e familiares com quem Queiroz conversou- em busca de escutar a voz desse Outro tão fortemente silenciado pela sociedade. Já em $O$ nascimento de Joicy, de Fabiana Moraes, a alteridade emerge modulada pelas questões de gênero e classe, pois Joicy é transexual, nordestina e pobre, e a reportagem conta sua árdua luta pelo direito de realizar a cirurgia de redesignação sexual pelo Sistema Único de Saúde (SUS).

As duas reportagens são animadas por problemáticas diversas, contudo, o que nos permite aproximá-las é a disposição para o encontro com o Outro, bem como o evidente interesse em retirá-lo de sua zona de invisibilidade. Em ambos os trabalhos, as repórteres resistem aos limites da escrita jornalística, codificada por técnicas e formatos, e buscam a retórica testemunhal e reflexiva, que desponta como saída ética no encontro com as vidas desconhecidas. Com a narração em primeira pessoa, Queiroz e Moraes problematizam seu lugar de observadoras, contribuindo com reflexão importante para o campo do jornalismo: as possibilidades e os limites existentes na relação entre jornalistas e personagens. Mais que isso, as experiências narrativas chamam a atenção para um fazer jornalístico posicionado, que não pretende esconder sua mediação, exercendo o testemunho do que viram e ouviram para produzir seus relatos. Devido à natureza particular dessas reportagens, buscaremos, mais adiante, desenvolver uma breve reflexão sobre as aproximações existentes entre o campo do jornalismo e da antropologia, acionando a contribuição de autores (SOUZA, 2010; GIRARDI JUNIOR, 2000) que qualificam os repórteres como "mediadores culturais".

Durante nosso percurso, retomaremos o entendimento de que, historicamente, a reportagem cumpriu o papel de descobrir espaços outros da sociedade, articulando relações importantes com o cotidiano e colocando-se como locus potencial de tensionamento das representações sociais hegemônicas.

Nosso pressuposto é de que a cultura é um terreno de disputas simbólicas, onde as representações tornam sensíveis e visíveis as lutas existentes na sociedade. Nesse terreno, 
as reportagens tanto plasmam os enfrentamentos simbólicos, como tornam-se narrativas importantes, com reverberações na ética do cotidiano. Para melhor delinear tal perspectiva, que permite uma visada crítica sobre a cultura contemporânea, retomaremos, na próxima seção, o marco histórico da virada cultural - momento em que diversos intelectuais passaram a considerar a cultura como uma arena de luta social e política.

\section{Por uma crítica da cultura contemporânea}

No livro A cultura na era dos três mundos (DENNING, 2005), Michael Denning discute o quanto os processos sociais globais se modificaram, no século XX, quando a cultura passou para o primeiro plano. Se até os anos 1950 os historiadores se limitavam a incluir a cultura num capítulo sobre artes, afirma o autor, subitamente, na era dos três mundos": "Todos descobriram que a cultura havia sido produzida em massa como os carros Ford; as massas tinham cultura e a cultura tinha uma massa. A cultura estava por toda parte, não era mais propriedade dos cultos e cultivados." (DENNING, 2005, p. 9).

Segundo Denning, a expansão da forma mercadoria foi o fator definitivo a apontar o quanto as grandes noções modernistas de cultura (o sentido de artes e letras e o sentido antropológico) tornaram-se insuficientes para abarcar os novos fenômenos das indústrias culturais. Novas concepções de cultura surgiram e movimentos sociais ao redor do mundo inventaram uma política da cultura, ao mesmo tempo em que batalhas intelectuais sobre seu significado foram travadas. Em anos recentes, escreve Denning, esse fenômeno ficou conhecido como "virada cultural" nas Ciências Humanas e Sociais, sendo associado à ascensão dos Estudos culturais. Contudo, prossegue o autor, a virada cultural eclodiu em todo o planeta, e mesmo aqueles que rejeitaram a palavra cultura (por razões ideológicas), fizeram parte dela: "A escolha que fazem de signo, ideologia, discurso, comunicação, consumo, vida cotidiana ou habitus como nome para a região que outros chamam de cultura é, em si mesma, parte do debate que constitui a virada cultural." (DENNING, 2005, p. 10). Nas diferentes regiões do globo, tornou-se patente que a cultura havia se retirado definitivamente da esfera espiritual para ocupar o cotidiano. Com a multiplicação dos meios

\footnotetext{
1 De acordo com Denning, a era dos três mundos pode ser considerada: “O curto período de século (1945-1989) em que imaginávamos o mundo dividido em três - o Primeiro Mundo capitalista, o Segundo Mundo comunista e o Terceiro Mundo em descolonização -, como se cada um fosse um planeta distinto envolvido em uma órbita elaborada e perigosa em volta dos demais." (DENNING, 2005, p. 10).
} 
de comunicação, novas formas de sociabilidade e organização coletiva se estabeleceram. Os conteúdos políticos e suas ligações com determinações econômicas tornam-se cada vez mais evidentes em empreendimentos da cultura de massa, evidenciando o amálgama do mundo da produção (antes restrito à economia) ao mundo das ideias. Para os pensadores da Nova esquerda britânica², a cultura alcançara tamanha centralidade que não mais poderia ser negligenciada como uma arena de luta social e política. Com efeito, os meios de comunicação de massa deveriam, necessariamente, ser tomados como uma instituição política - devido ao seu poder de selecionar, enfatizar e excluir temas (CEVASCO, 2003).

Em evidente filiação ao programa dos Estudos culturais, Douglas Kellner (2001) identifica o advento de uma "cultura da mídia" na contemporaneidade, responsável pela disseminação de imagens, signos e mitos que produzem uma "cultura global", a partir da qual os sujeitos forjam valores e moralidades. Segundo Kellner, com a ampliação exponencial dos meios de comunicação, a cultura da mídia invadiu todos os recantos da vida, convertendo-se numa verdadeira força de socialização e tornando indiscerníveis os laços entre cultura e comunicação.

Para o autor, o melhor modo de investigar a cultura contemporânea, com foco sobre as conexões entre mídia e sociedade, é a realização do estudo cultural crítico. Uma perspectiva crítica, propõe Kellner, compreende a cultura como algo inerentemente político, terreno de disputas, onde representações podem aliar-se às formas de resistência e contrahegemonia ou às forças de dominação. Conforme pontua Kellner:

0 estudo cultural crítico tenta mostrar como certas figuras e certos modelos e discursos solapam os valores e o ethos de uma sociedade pluralista, igualitária, democrática e multicultural, ao passo que outros podem preconizar a criação de uma sociedade mais igualitária e democrática. (KELLNER, 2001, p. 133).

Não por acaso, os discursos veiculados pela mídia são conflitantes e contraditórios. Como consequência, a cultura da mídia não deve ser compreendida como instrumento

\footnotetext{
${ }^{2}$ A New left foi um movimento intelectual britânico que, a partir dos anos 1950, buscou instaurar novas formas de reflexão e prática políticas. Seus intelectuais buscaram uma interpretação socialista do mundo e sua atuação mais duradoura foi no terreno da cultura. A New left constituiu a base dos Estudos Culturais (CEVASCO, 2003).
} 
exclusivo de dominação, pois ela abriga, igualmente, representações contestatórias aos poderes.

As noções apresentadas por Douglas Kellner encontram ressonância no pensamento de Stuart Hall (2016), sobretudo, em suas teorizações sobre as representações sociais. Hall desenvolveu sua análise política da cultura a partir da noção específica de representação. Como construtivista, o autor relegou o conceito de representação a um plano de ação. Segundo Hall, todo "real" é uma "construção social", amplamente influenciada pela mídia e as imagens por ela disseminadas no mundo contemporâneo. Assim, devem ser as representações o objeto por excelência de uma análise crítica do real. Isso significa escrutinar os valores contidos nas imagens e textos, e, além deles, em busca daquilo que representam culturalmente.

Nos termos propostos por Stuart Hall, pensar a cultura é considerar os mapas conceituais compartilhados socialmente, que possuem os códigos de valoração dos elementos do mundo. Tais códigos fixam as relações entre os conceitos e os signos e fornecem as referências a serem acionadas para expressar determinada ideia, dentro de diferentes linguagens e culturas distintas. A constatação aqui é de que a relação de sentido entre os conceitos e os signos não está dada de antemão, nem fixada na natureza. Trata-se, antes, de uma relação que emerge das convenções sociais, porque as culturas é que decidem e acordam entre seus membros quais signos representarão determinados conceitos. 0 sentido é, pois, invariavelmente construído, produzido em práticas significantes no interior da cultura, e, precisamente por ser produto de convenções, o signo jamais poderá ser fixado. Hall explica que desde o marco histórico da virada cultural nas Ciências Sociais e Humanas, o sentido é visto como algo a ser construído, em vez de simplesmente encontrado.

Essas asserções levam à compreensão de que a representação é a produção de sentido pela linguagem; com efeito, o mundo material (no qual as coisas existem) não deve ser confundido com aquele das práticas e processos simbólicos, onde a representação opera. Valores e ideologias sobre o mundo material são compartilhados socialmente por meio das representações. Não por acaso, Stuart Hall situa a representação como um conceito e como uma prática de produção de significados no circuito cultural.

Em muitos de seus escritos, Hall forneceu a dimensão do quanto as representações da alteridade são moduladas ideologicamente. Num de seus textos fundamentais, $O$ espetáculo do Outro (HALL, 2016), o autor discute uma série de práticas produzidas em 
representações ocidentais, que pretenderam estabelecer distâncias entre o mundo branco e africano. Tais representações tentaram fixar significados sobre o que é a raça; e se tornaram responsáveis pela disseminação do imaginário sobre o negro no Ocidente. "A tentativa de fixação é o trabalho de uma prática representacional que intervém nos vários significados potenciais de uma imagem e tenta privilegiar alguns deles." (HALL, 2016, p. 143). Contudo, sugere o autor, existem formas contestatórias e contraestratégias de representação que impulsionam o significado a deslizar, sendo redirecionado, insurgindo-se sobre os antigos. A palavra "preto" foi secularmente associada à sujeira, a tudo que era escuro, mau e diabólico, afirma Hall, mas a percepção sobre as pessoas negras nos Estados Unidos se modificou nos anos 1960, depois que o slogan Black is beautiful circulou, permitindo que o significado deslizasse.

Essas contribuições teóricas nos autorizam a situar o campo da representação como locus de disputa, no qual emergem formas dissonantes e contestatórias aos discursos hegemônicos. É nessa arena conflitiva que se insere nosso objeto empírico: as reportagens realizadas por Nana Queiroz e Fabiana Moraes, narrativas portadoras de estratégias discursivas que rearticulam sentidos sobre a diferença, convocando os leitores a partilhar suas formas sensíveis.

\section{Práticas comunicacionais, produção de sentidos e cotidiano}

Antônio Fausto Neto (2008) identifica a intensa midiatização dos processos sociais na sociedade contemporânea. Para o autor, nas últimas décadas, a tecnologia converteu-se no principal dispositivo organizador de sentidos da vida social, tendo em vista os protocolos técnicos, que transformam as tecnologias em meios de produção, circulação e recepção de discursos, modificando profundamente os processos simbólicos e interacionais da sociedade. Ao contrário do que ocorria na antiga sociedade dos meios, argumenta Fausto Neto, na sociedade atual as mídias perdem seu lugar de auxiliaridade para se tornarem instância engendradora dos modos de vida e referência primordial na construção social da realidade.

De acordo com Fernando Resende (2005), nesse contexto de exacerbação do espaço midiático, há o reordenamento das relações espaço-temporais e dos campos sociais. "As 
sociabilidades se configuram por vias mediatizadas, a noção de espaço público, como lugar simbólico em que se tecem relações sociais, ganha relevos significativos." (RESENDE, 2005, p. 86). Conforme observa o autor, variados campos e organizações sociais coexistem nesse cenário, estabelecendo correlação de forças. Trata-se de um espaço público conflituoso que articula os saberes e as práticas do cotidiano; assim o campo da mídia se sustenta como agente autônomo, mas também dependente: "Ele instaura, ao mesmo tempo em que conforma e redefine, discursos sobre a sociedade; ou seja, ele cria e recria práticas sociais discursivas que tanto desejam falar da sociedade como se constituir enquanto saber acerca desta mesma sociedade." (RESENDE, 2005, p. 86).

César Guimarães e Vera França, em reflexão sobre as práticas comunicacionais na sociedade atual, contrapõem perspectiva relacional à visão dicotômica que buscou, ao longo de décadas, enfatizar os efeitos da comunicação sobre a vida social, bem como sua utilização operacional por certas instâncias, como a política e a econômica, para se atingir determinados fins:

As práticas comunicativas - oriundas da interseção entre a mídia e a sociedade - são constituidoras da vida social, ao mesmo tempo, constituídas por ela - o que altera completamente (mas também dificulta) a forma de abordá-las. (GUIMARÃES; FRANÇA, 2006, p. 90).

A partir da possibilidade dialógica apontada pelos autores, que retira a comunicação de sua função transmissiva para encará-la como locus fundamental de constituição de discursos na esfera pública e de interlocução na vida social contemporânea, é que indagamos como a mídia e, mais precisamente, o campo do jornalismo, tem constituído repertórios sobre a alteridade nas narrativas que produz. Sobretudo, quando consideramos o jornalismo como uma forma de conhecimento necessariamente vinculado à vida cotidiana (MEDITSCH, 1992), e, consequentemente, mediador social fortemente inserido no terreno da experiência.

Ao refletir sobre os "modos de fala" dos jornais, discutindo a representação da diferença, Fernando Resende (2007) observa que a referência a Foucault se torna fundamental. Ele retoma o pensamento do filósofo francês sobre a "vontade de verdade", com o intuito de considerar os discursos produzidos pelos produtos jornalísticos. Para Resende, se Foucault havia enxergado nas sociedades do saber instâncias legitimadoras das 
falas que se pretendiam verdadeiras, hoje, a mídia, com todo o seu aparato institucional, desponta com instância crucial: "Certamente reguladora e mantenedora de um status quo que visa à ordenação dos fatos que tecem nossas relações sociais." (RESENDE, 2007, p. 83). Os discursos jornalísticos, prossegue Resende, despontam como a expressão máxima da verdade na contemporaneidade, modulando nossas visões de mundo e nossa perspectiva em relação à diferença.

Não por acaso, as narrativas jornalísticas estão fortemente vinculadas às disputas por sentido na sociedade. Elas contribuem para compreendermos o mundo; são instâncias de produção e partilha de significados, articulando saberes e imiscuindo-se ao contexto geral da experiência. Como propõe Fernando Resende, as narrativas:

Têm um papel relevante, primeiro porque nelas são tecidos os saberes acerca do mundo, depois porque, a partir delas, outros saberes são construídos. Em outras palavras, se há uma mediação possível, pelo menos em se tratando do campo dos media, ela acontece na e através da narrativa. (RESENDE, 2005, p. 87).

Não por acaso, Roger Silverstone (2002) afirma que a investigação do modo como entramos em relação com a alteridade, pela mediação das imagens e dos discursos da mídia, se torna fundamental, pois:

É, de fato, na relação com a mídia, com a comunicação e a representação mediadas que cada vez mais temos de nos posicionar como sujeitos morais, pois muitas vezes o Outro aparece para nós apenas sob esse aspecto, e essas representações são checadas, quando possível, à luz das experiências da vida cotidiana. (SILVERSTONE, 2002, p. 259).

Silverstone escreve que no mundo contemporâneo, em muitas situações, a alteridade somente passa a existir quando exibida e problematizada nos espaços da mídia. Se as narrativas criadas pelos meios de comunicação ocupam espaço tão crucial, é tarefa capital compreender a atitude dos jornalistas na aproximação aos espaços do Outro, quando imbuídos da tarefa de produção da reportagem. 


\section{Reportagem e alteridade: o encontro de mundos na tessitura da narrativa jornalística}

Há muito os jornalistas têm enfrentado o desafio de representar o Outro, "traduzindo", por meio de suas narrativas, culturas e modos de vida presentes na sociedade. Em contato com diferentes espaços e grupos sociais, eles atuam como mediadores culturais (SOUZA, 2010; GIRARDI JUNIOR, 2000), utilizando métodos de abordagem como a observação direta, a entrevista e o testemunho do que viram e ouviram para produzir seus relatos. Essa prática suscita aproximações entre o campo do jornalismo e da antropologia, frequentemente retomadas por pesquisadores.

Cláudia Lago (2008) comenta que as relações entre os dois campos não são recentes. Em reflexão sobre os métodos de pesquisa sedimentados pela antropologia e empregados pelo jornalismo, a autora lembra que, já no início do século XX, a "Escola de Chicago voltou seu olhar para o meio urbano e estudou sua relação com a mídia a partir de um trabalho com feições antropológicas." (LAGO, 2008, p. 48). Com o passar dos anos, acrescenta Lago, a relação estreitou-se, tendo se tornado evidente a influência dos métodos de trabalho da antropologia em pesquisas do campo da comunicação e do jornalismo, a exemplo do newsmaking, cuja investigação se fundamentou na etnografia, privilegiando a observação detida ao ethos profissional dos jornalistas.

Como explica Lago, a etnografia é um produto do trabalho antropológico, e, segundo formulação de Geertz, pode ser compreendida como: "Descrição densa de determinada cultura, a que tem acesso o antropólogo a partir de um intenso contato com essa cultura, feito em um tipo de trabalho de campo que, por sua vez, tem a observação participante como norteadora." (LAGO, 2008, p. 49).

Candice Vidal e Souza (2010) retoma o momento de concepção da reportagem no mundo ocidental, em fins do século XIX, para evidenciar como o trabalho dos repórteres portador de características como o relato da observação obtida no local dos acontecimentos - se aproxima daquele realizado pelo antropólogo:

A reportagem pode ser comparada à etnografia pelo valor do testemunho que oferece - "do ver com os próprios olhos". Ambas as formas de conhecimento compartilham relações com o gênero relato de viagem, 
retirando sua autoridade narrativa do fato do autor ter "estado lá". Outra semelhança está no registro de alteridades culturais que reportagens feitas no exterior - em outras nacionalidades - ou no interior de uma nação efetivamente realizam, tal como faz o texto etnográfico. (SOUZA, 2010, p. 82).

No caso do jornalismo brasileiro, continua Souza, a afirmação da reportagem como gênero narrativo, nas décadas de 1940 e 1950, confundiu-se com a consolidação da identidade social dos jornalistas. Naquele momento, se estabeleceram as bases do moderno jornalismo nacional, prevalecendo o ideal de que caberia à reportagem a "descoberta" do Outro e suas formas de vida. Os relatos de Canudos tiveram, pois, sentido fundador. Desde o ano de 1897, os jornais enviaram correspondentes ao local da Guerra de Canudos, para o front de batalha ou seus arredores. Como observa Souza, os registros de Canudos resultaram no "Surgimento da figura do repórter na imprensa brasileira e no aparecimento da reportagem como narrativa da observação direta realizada pelo autor presente." (SOUZA, 2010, p. 10).

A constituição desse método de trabalho foi crucial para conferir visibilidade a espaços outros, que não faziam parte das narrativas jornalísticas, até então. 0 modo de narrar também se modificou:

Surge um tipo de texto (que conta o que aconteceu, com quem, em que local, em que dia; introduz personagem e suas falas, descreve o cenário dos eventos e permite análises sobre o ocorrido) e um tipo de narrador que escreve para o jornal as impressões daquilo que viu ou tomou conhecimento. (SOUZA, 2010, p. 10).

Torna-se subjacente ao fazer jornalístico o compromisso de "descobrir o Brasil", sendo a reportagem instrumento de resgate da nação. 0 sujeito nômade das redações (que se distingue dos colegas que colaboram com o jornal por meio de textos opinativos ou analíticos) inaugura o perfil profissional que produz um tipo inédito de texto, baseado em informações sobre os acontecimentos do cotidiano.

Já no início do século XX, os repórteres se tornam uma espécie de síntese do que deveria representar a figura do jornalista: "Um agente mediador entre realidades sociais diversas." (SOUZA, 2010, p. 11). Agora, eles percorrem outros territórios, menos distantes, mas igualmente apartados simbolicamente da cidade formal. Entre os anos de 1900 e 1920, 
Paulo Barreto, o João do Rio, foi um dos pioneiros a fazer uso da observação direta e da entrevista. Ao sair das redações para as ruas, o repórter narrou o cotidiano do Rio de Janeiro, relatando a situação social dos locais desprivilegiados, como a realidade do morro Santo Antônio, já em 1908 considerado favela. Nas incursões que fez pelo espaço urbano, João do Rio buscou a vida anônima, concedendo visibilidade aos tipos marginais e párias sociais. No meio cultural de seu tempo, ele tangenciou os elementos basilares da reportagem, que, desde o início, trabalha na aproximação da informação e da vida.

Liráucio Girardi Junior recupera, contudo, os desafios que os repórteres enfrentam quando submetidos à "usina de textos" dos jornais diários - que mantêm como paradigma as regras da objetividade 3 . Para o autor, os procedimentos práticos do jornalismo acabam se transformando num roteiro que o repórter deve seguir. Elaborada sob essa lógica, a reportagem acabaria se aproximando mais de "Caricatura da etnografia, na qual falta uma preocupação com a totalidade, com a inserção do acontecimento cotidiano na totalidade das práticas vividas no bairro ou na cidade." (GIRARDI JUNIOR, 2000, p. 5). Porém, uma coadunação à etnografia se viabilizaria nas reportagens em profundidade:

Na grande reportagem, que não deixa de ser um apressado trabalho de campo, o repórter pode transformar-se em um "etnógrafo" de sua própria sociedade ou dos diversos grupos e acontecimentos que ela comporta. Situações e histórias de vida que transformam homens e grupos sociais em outros, aqueles que nos causam espanto, atraem nossa ira ou curiosidade por serem diferentes, imersos em um mundo sobre o qual temos pouca informação (e, assim, uma boa dose de preconceito) e que ao mesmo tempo fazem parte do fragmentado imaginário de nossa sociedade. (GIRARDI JUNIOR, 2000, p. 6).

Cláudia Lago sustenta posição parecida a de Girardi Junior, pois aposta que a antropologia é rica em procedimentos para auxiliar a reflexão noutros campos de saber, mas

\footnotetext{
${ }^{3}$ A objetividade é uma concepção que emergiu nos Estados Unidos por volta de 1920; embora seja extremamente questionada pelo pensamento crítico por ser incapaz de explicar os modos de produção da atividade jornalística, é largamente aceita e reconhecida pelo campo profissional. Em estudo de referência para a área do jornalismo, Gaye Tuchman afirma que a objetividade pode ser considerada um "ritual estratégico" adotado pelos jornalistas para se proteger, auxiliando-os a atestar que suas posições pessoais não prejudicam a exatidão do trabalho. Segundo Tuchman, os recursos utilizados no meio profissional para sustentar a concepção de objetividade são puramente formalistas, tais como "ouvir os dois lados"; utilizar aspas para indicar que os profissionais não estão fornecendo sua versão dos acontecimentos; apresentar o fato mais importante em primeiro lugar (uso da pirâmide invertida). Para a autora, esses procedimentos somente: "1) Constituem um convite à percepção seletiva, 2) insistem erradamente na ideia de que os fatos falam por si, 3) são instrumentos de descrédito e um meio do jornalista fazer passar sua opinião, 4) são limitados pela política editorial de uma determinada organização jornalística, e 5) iludem o leitor ao sugerir que a análise é convincente, ponderada ou definitiva." (TUCHMAN, 1999, p. 89).
} 
convoca alguns ajustes na interface com o jornalismo. Uma primeira questão a ser levantada, diz a autora, é que as pesquisas do jornalismo, quando interagem com a antropologia, priorizam a "Aplicação quase que mecânica do método, perdendo com isso o olhar disciplinado pela antropologia, fundamentalmente marcado pela suspeição em relação à própria pesquisa." (LAGO, 2008, p. 55). Tal ausência de reflexão incide, por exemplo, sobre o procedimento da observação direta, quando adotado pelos jornalistas.

A observação direta é uma das discussões mais antigas da antropologia, explica Lago, e está ligada às indagações sobre a subjetividade do pesquisador no encontro com o Outro, bem como ao seu papel como integrante do universo de pesquisa. A autora afirma, no entanto, que tal dimensão é praticamente ignorada em pesquisas do jornalismo que se valem do pensamento antropológico. Sobretudo, porque o campo jornalístico é marcado por forte auto-referencialidade, o que, muitas vezes, leva os pesquisadores a validarem os pressupostos compartilhados pela sua área.

Lago lembra que há muitas batalhas travadas no interior da disciplina da antropologia sobre a questão da subjetividade do pesquisador. Esse debate, explica, se acirrou com as incertezas inerentes à perspectiva pós-moderna que, desde o fim dos anos 1980, endereçou forte crítica ao papel do autor no texto etnográfico. Tais posições defenderam a "Impossibilidade da escritura (ou da etnografia) ou, numa hipótese menos cética, a necessidade de incorporação de todas as vozes presentes no encontro (tomado como confronto) do campo." (LAGO, 2008, p. 58). Depois de muito debate no meio antropológico, prevaleceu:

A compreensão praticamente generalizada de que a questão da subjetividade coloca a necessidade de se refletir, na pesquisa, sobre a relação sujeito/objeto. E concluir, no mais das vezes, que ambos fazem parte do mesmo universo, que não há neutralidade nesse encontro permeado pelas subjetividades de ambos. 0 problema passa a ser, portanto, como inserir essa subjetividade no contexto da pesquisa, como processá-la. (LAGO, 2008, p. 59).

Se tais questões sobre a subjetividade são profícuas no âmbito da antropologia, pergunta a autora, "Por que tendem a ausentar-se quando o método migra para o jornalismo?" (LAGO, 2008 p. 59). Estamos cientes de que, com tal indagação, Cláudia Lago busca discutir o papel do pesquisador no campo "acadêmico" do jornalismo, tomando como 
objeto as pesquisas realizadas na área. Contudo, acreditamos que tal reflexão deva balizar também o terreno das práticas, pois justamente nessa seara os jornalistas fazem valer mais fortemente os pressupostos compartilhados por sua comunidade interpretativa, como aqueles relativos à objetividade.

E como pensar nas possibilidades de aprendizagem sobre outros povos e outras culturas advindas do encontro de subjetividades que a reportagem jornalística suscita, quando o campo sequer reconhece que exista um autor para as narrativas que produz? Como já observamos neste artigo, o discurso tradicional do jornalismo é objetivo. Para que tenha existência no texto, seu autor deve manter-se na posição de observador, pois o universo narrado jamais poderá ser conformado à sua subjetividade. Trata-se, assim, de um narrador que se apaga - o que se torna um complicador para a abertura a procedimentos dialógicos, que incorporem elementos da subjetividade do Outro e permitam que algo do seu universo possa se afirmar na narrativa jornalística.

Para nós, a relação sujeito/objeto e o contato intersubjetivo se fazem decisivos na situação da reportagem, pois é a partir da relação entre quem observa e quem é observado que a enunciação se conforma - quando o repórter deve escolher recursos narrativos que, em sintonia, permitam porosidades por onde se insinuem as formas singulares do viver. Ao procurarmos compreender como as narrativas jornalísticas posicionam o Outro, fazendo-o existir por meio de seus relatos, devemos perguntar, igualmente, pelos modos de aproximação ao universo narrado. Não basta conferir visibilidade ao Outro, é preciso conjugar procedimentos de abordagem e recursos expressivos que evitem dominá-lo, transformando sua representação numa tradução turística ou publicitária.

Concordamos com Cremilda Medina (2014), quando a autora argumenta que, na produção da reportagem, uma estética inovadora não se separa dos modos de incursão ao "mundo vivo". Para Medina: "O contato e a observação da cena real desafiam a produção simbólica para a compreensão complexa, diga-se, contraditória, conflitiva e exige do repórter a desconstrução de travas ideológicas alimentadas por certezas." (MEDINA, 2014, p. 12). Assim, continua a autora, na fricção com o mundo do Outro, o jornalista será impelido à tessitura narrativa que acolha as vozes anônimas da sociedade, criando um relato polifônico e democrático. 
Descrever alguns aspectos do método de trabalho adotado por Nana Queiroz e Fabiana Moraes, que nos auxiliem a refletir sobre a relação sujeito/objeto na produção das reportagens, é a tarefa que assumimos na próxima seção.

\section{Narrativas jornalísticas dissonantes: o eu-narrador de Nana Queiroz e Fabiana Moraes}

As reportagens Presos que menstruam, de Nana Queiroz, e $O$ nascimento de Joicy, de Fabiana Moraes (ambas publicadas em 2015), têm em comum a forma de abordagem, pois as repórteres optaram pela observação participante - escolha que demandou, além de aproximação considerável aos espaços e personagens narrados, investimento de tempo que extrapolou, em muito, aquele das rotinas cotidianas do jornalismo convencional. Os dois relatos foram produzidos em primeira pessoa, atestando o desvio de uma escrita jornalística formatada pelos padrões hegemônicos. Ancoradas no "eu”, Fabiana Moraes e Nana Queiroz apresentaram reportagens cuja produção de sentidos mostrou-se estreitamente ligada às suas experiências subjetivas e a de seus personagens.

Em ensaio sobre o tema, Erik Neveu (2016) relembra o entusiasmo que sentiu quando entrou em contato com as narrativas do new journalism - como as de Tom Wolfe, Michael Herr e Hunter Thompson. "As narrativas pareciam, de alguma forma, falar de um mundo verdadeiro e mais fascinante." (NEVEU, 2016, p. 30). Na visão do autor, os escritoresjornalistas ${ }^{4}$ atribuíam, em seus relatos, profundidade às descrições. Ao fazê-lo, tocavam o cerne de uma questão cara à prática das Ciências sociais, que gravita em torno de compreender "como" falar com a sociedade. Se as reportagens do new journalism propuseram interessante diálogo com o conjunto social, pondera Neveu, é porque mergulharam no ordinário da vida comum, mostrando os detalhes, as situações cotidianas, os estilos de vida e fornecendo novos prismas de leitura da sociedade.

Ao esboçar um quadro geral sobre narrativas dessa natureza, o sociólogo francês elenca algumas características importantes de sua composição, dentre elas, a imersão (associada ao longo investimento de tempo na investigação dos temas escolhidos) e a

\footnotetext{
${ }^{4}$ Neveu considera "escritores-jornalistas" nomes como Hemingway e Steinbeck, mas também os muckcrackers - os jornalistas estadunidenses que no início do século XX denunciavam a miséria social, realizando uma prática que mais tarde seria retomada pelo new journalism.
} 
reflexão sobre as formas de escrita, quando os jornalistas saem em busca de estratégias narrativas que possam sustentar a representação ética das vidas desconhecidas.

Podemos encontrar ecos dos elementos apontados por Neveu nas reportagens brasileiras discutidas neste artigo. Em Presos que menstruam, Nana Queiroz acompanhou o cotidiano nos presídios femininos brasileiros durante quatro anos. Em sua jornada, a repórter esteve em mais de dez presídios existentes no país, tendo trabalhado como voluntária numa instituição carcerária para se tornar mais próxima do universo sobre o qual escrevia. Noutros momentos, Queiroz se fez passar por amiga de infância de presas, acampou na porta de presídios e aproximou-se das famílias das detentas para conseguir acesso a informações e entrevistas.

A reportagem de Queiroz apresenta os relatos de sete presidiárias, que revelam desde os episódios que as levaram à prisão, até seu cotidiano no cárcere. A esses depoimentos somam-se vozes de outras tantas presas com quem Nana Queiroz conversou. Em conjunto, as falas dessas mulheres anônimas fornecem uma visão ampla sobre a cultura e a vida no cárcere - desde as condições gerais de tratamento, os códigos compartilhados, a constante violência, os castigos, a comida estragada e a falta de limpeza nas celas; até os elementos que preenchem os afetos, como a amizade e o namoro com outras presas, a dor pela separação dos bebês que gestaram cumprindo pena, a decepção pelo abandono dos companheiros que ficaram do lado de fora, a saudade dos familiares e as alegrias nos dias de visitas.

Em muitos pontos da reportagem, Queiroz se apresenta como testemunha desses relatos pessoais; ela narra o cenário da conversa, as perguntas feitas, as entonações e gestos das presas, as dúvidas que sentiu, os calafrios que percorreram seu corpo. No texto, a experiência da repórter desponta como parte determinante do universo narrado.

Essa perspectiva testemunhal ganha nuances interessantes nos momentos em que Queiroz revela os dilemas éticos enfrentados, como o desafio de produzir uma reportagem que jamais poderia transformar suas personagens em vítimas - ao mesmo tempo em que seu envolvimento na reportagem a colocava frente à ambiguidade inerente à natureza humana. Tais reflexões surgiram no processo de investigação da história das presas, como se depreende do seguinte trecho: 
O momento mais duro em que essa balança se pôs diante de mim se deu alguns meses depois de minhas visitas à oficina de trabalho na Funap, no centro de São Paulo. Resolvi consultar os processos das mulheres que eu havia entrevistado para averiguar a versão da Justiça sobre seus casos. Fiz questão de lê-los algum tempo depois de as entrevistas terem terminado não queria ir para as conversas com nenhum viés. Assim, conheci as inconsistências do processo de Camila, a provável cumplicidade de Júlia com o ex-namorado - talvez por medo, talvez por amor, como ela havia me contado -, os detalhes sórdidos do sequestro em que Vera esteve envolvida. Chegaram em minhas mãos, então, os documentos de Gardênia. Àquela altura eu tinha me afeiçoado por seu jeito desparafusado e suas gargalhadas sem motivo [...]. Quando abri o documento comecei a tremer. Não podia acreditar que aquela mulher risonha que eu conhecera tinha sido capaz de algo tão torpe. De repente, os pontos se juntaram. Fez sentido que ela tivesse cumprindo pena em Tremembé. Gardênia era acusada de assassinar uma criança. Não qualquer criança, vale ressaltar, mas seu próprio filho. (QUEIROZ, 2015, p. 222).

É a partir de passagens como esta que a narrativa de Presos que menstruam se constitui, revelando, no modo mesmo de articulação do relato, a relação de alteridade. Se a narrativa privilegia a apresentação do universo desconhecido do presídio e da vida de seus atores, o uso do eu-narrador deixa salientes os traços da relação intersubjetiva, descortinando a dimensão afetiva na constituição do narrado - o que acrescenta novos sentidos à reportagem.

Em $O$ nascimento de Joicy, trata-se também de percorrer o espaço menos iluminado da vida. Em 2010, a repórter Fabiana Moraes, do Jornal do Commercio-j de Pernambuco, resolveu contar a história de uma transexual que se submeteria à cirurgia de redesignação sexual pelo Sistema Único de Saúde (SUS). A ideia era acompanhar uma mulher não biológica desde os procedimentos preparatórios para a cirurgia até o resultado final, depois da mudança no corpo. Neste caso, a imersão de que fala Erik Neveu, se daria pela permanência constante ao lado de uma paciente - durante a internação - mas também no cotidiano, na volta para casa.

Com tal proposta, Fabiana Moraes dirigiu-se ao setor de ginecologia do Hospital das Clínicas do Recife, em busca de um perfil que pudesse compor a reportagem. No local, a repórter encontrou muitas mulheres não biológicas buscando o apoio do SUS para realizar o procedimento; mas, dentre todas, foi Joicy quem mais lhe chamou a atenção. Joicy era o nome adotado por João Batista, ex-agricultor pobre de Alagoinha (PE) que lutou durante 
oito anos pelo direito de realizar a cirurgia de redesignação sexual pelo serviço público de saúde. 0 acompanhamento de Fabiana Moraes à Joicy começou naquela manhã.

No dia 22 de novembro de 2010, menos de dois meses depois do primeiro encontro, Moraes registraria o nascimento de Joicy Melo da Silva, aos 51 anos, após a cirurgia, que foi bem-sucedida. Ao nascer, a transexual deixava para trás o corpo de João Batista, o agricultor que jamais aceitara sua condição masculina. Na reportagem em que Moraes narrou a estadia de Joicy no hospital, contando como foram os últimos instantes vividos no corpo de João e como se desenvolveu a recuperação ("difícil" e "solitária") da transexual, coube também um recuo ao passado. Na digressão, Moraes recuperou a infância pobre de João Batista, sua relação com as irmãs e a decisão pelo procedimento de redesignação sexual, logo após a morte do pai. De volta ao presente, a narrativa revelou o cotidiano árduo da transexual, descrevendo a vida precária de Joicy no barracão exíguo onde morava, no qual, às vezes, a comida faltava. Mas também nuançou os afetos da cabeleireira, como seu gosto particular por sucessos musicais internacionais e o carinho especial por Dorneles, o amigo-amor.

Com tamanha investida no universo do Outro, a escrita de Moraes forneceu, em boa medida, a singularidade da personagem, desidentificando-a de padrões e categorias, nuançando sua existência única, que não autoriza generalizações. A história da vida de Joicy foi publicada numa série de reportagens, durante três dias, num caderno especial do Jornal do Commercio. 0 resultado do trabalho tornou Fabiana Moraes vencedora do Prêmio Esso, em 2011.

Pouco tempo depois, a repórter retomaria o assunto, agora tensionando as formas de escrita e narrando os acontecimentos em primeira pessoa, numa reportagem que ganhou o formato de livro. O nascimento de Joicy se constitui de três partes: na primeira estão reproduzidas as reportagens publicadas no Jornal do Commercio; a segunda parte é reflexiva, consistindo numa espécie de paratexto que acompanha o texto anterior. É neste momento que Moraes aciona o eu-narrador e revela os modos de produção da reportagem, os encontros com Joicy, sua família e a equipe médica. Nesse relato, a autora realça o quanto o encontro com a transexual foi modulada por afetos e conflitos, fornecendo a dimensão complexa do encontro de alteridades, inevitavelmente modulado por diferenças de perspectivas, que nem sempre ficam distantes do "ambiente da pauta". Como revela a repórter: 


\begin{abstract}
Brigávamos várias vezes, em discussões nas quais não estava claro quem era a antagonista (mas, de fato, existiu uma?). Censurei-a outras tantas, principalmente pelo modo pouco suave com o qual cuidava de si, pelo modo pouco suave com que lidava com a família. Hoje vejo que ali eram os meus valores os atingidos negativamente, e, por mais que eu tentasse domar minha reação e minha dor, nem sempre era possível mantê-los distantes do ambiente da pauta. Como apagá-los ao me ver em situações permeadas por tantos conflitos e intimidade? (MORAES, 2015, p. 20).
\end{abstract}

Não por acaso, na terceira parte de $O$ nascimento de Joicy, a autora tece uma discussão teórica sobre a relação entre jornalistas e personagens, acionando contribuições das diversas áreas das Ciências Sociais. Moraes defende que as teorias jornalísticas exploram muito timidamente o aspecto relacional com as fontes, limitando-se a classificá-las entre graus de importância e interesse. Para ela, o debate sobre a relação entre os repórteres e seus personagens precisa urgentemente ser realizado no campo jornalístico. "Jornalista e fonte/personagem nunca estão estanques ou passivos. Eles podem facilmente sair de suas peles para transmutar-se naquilo que o outro não conhecia - e é justamente aí que reside boa parte do assombro, da dor, do suor e da alegria." (MORAES, 2015, p. 18).

Pela sua constituição, $O$ nascimento de Joicy pode ser compreendida como uma grande reportagem que se adensa. Ao apresentar o paratexto, de caráter reflexivo, Fabiana Moraes confere outra espessura ao narrado: mais que mostrar os bastidores da produção, ela propõe um jornalismo subjetivo, que não pretende esconder as incompletudes próprias à realização da reportagem. Ao incorporar as diferenças advindas do encontro de alteridades no espaço narrado (sem buscar apartá-las), o relato se torna mais aberto e polifônico, abrindo possibilidades para que algo do mundo do Outro se afirme.

\title{
6 Considerações finais
}

Em O nascimento de Joicy e Presos que menstruam, Moraes e Queiroz contribuem com reflexão importante para o campo do jornalismo: a problematização do seu lugar de observadoras, reconhecendo as assimetrias inerentes à relação entre jornalistas e personagens. Não por acaso, as reportagens deixam ver as dificuldades presentes no processo de realização. A escrita incorpora ruídos e incompletudes. Diante da missão nada fácil de encontrar o Outro e dizer sobre o seu mundo, Moraes e Queiroz escolhem textos 
menos apegados a verdades absolutas, quantitativas. A saída ética que buscam é a reflexividade. São trabalhos que se colocam em perspectiva, que se reconhecem como subjetivos.

Identificar os traços que distinguem essas reportagens é também buscar compreender em que medida elas resistem aos poderes que concebem a representação da diferença emoldurada por estratégias puramente comerciais ou estereotipadas, não poucas vezes oferecida por relatos que mascaram as distâncias em relação ao Outro, causando a falsa impressão de proximidade.

No caso brasileiro, investigar quais têm sido os investimentos das narrativas jornalísticas para conferir visibilidade aos espaços de alteridade é fundamental. "A disputa pelo controle das representações, que existe no mundo inteiro, no Brasil assume significados específicos, uma vez que o controle sobre o que será representado, como e onde, está imbricado com os mecanismos de reprodução da desigualdade social". (HAMBURGER, 2005, p. 197).

Como observa Douglas Kellner (2001), é por meio das imagens, espetáculos e narrativas que os sujeitos se asseguram dos confrontos existentes no mundo social. Sob essa perspectiva, as reportagens de Fabiana Moraes e Nana Queiroz plasmam algo dessas disputas, propondo formas contestatórias de representação da alteridade.

Pela maneira como escolhem se aproximar dos sujeitos ordinários e narrar suas vidas, deixando conformadas no texto as marcas do encontro com o Outro, as narrativas evitam a apreensão unívoca dos universos abordados. Eis aí alguma chance para que a singularidade e voz do Outro compareçam no relato, que, por isso mesmo, pode ser considerado mais dialógico e polifônico.

\section{Referências}

CEVASCO, Maria Elisa. Dez lições sobre os estudos culturais. São Paulo: Boitempo Editorial, 2003.

DENNING, Michael. A cultura na era dos três mundos. São Paulo: Religare, 2005.

FAUSTO NETO, Antônio. Fragmentos de uma "analítica" da midiatização. Matrizes, São Paulo, n. 2, p. 89-105, abr. 2008. 
GAYE, Tuchman. A objetividade como ritual estratégico: uma análise das noções de objetividade dos jornalistas. In: TRAQUINA, Nelson (org.). Jornalismo: questões, teorias e "estórias". Lisboa: Vega, 1999. p. 74-90.

GIRARDI JUNIOR, Liráucio. A reportagem como experiência etnográfica. Anuário de Jornalismo, [S.I.], v. 2, n. 2, p. 198-213, 2000.

GUIMARÃES, César; FRANÇA, Vera. Experimentando as narrativas do cotidiano. In: GUIMARÃES, César; FRANÇA, Vera (orgs.). Na mídia, na rua: narrativas do cotidiano. Belo Horizonte, Autêntica, 2006. p. 89-108.

HALL, Stuart. Cultura e representação. Rio de Janeiro: Ed. PUC-Rio: Apicuri, 2016.

HAMBURGER, Esther. Políticas da representação. In: MOURÃO, Maria Dora; LABAKI, Amir (orgs.). 0 cinema do real. São Paulo: Cosac Naify, 2005. p. 197-215.

KELLNER, Douglas. A cultura da mídia: estudos culturais: identidade e política entre o moderno e o pós-moderno. São Paulo: EDUSC, 2001.

LAGO, Cláudia. Antropologia e jornalismo: uma questão de método. In: LAGO, Cláudia; BENETTI, Marcia (orgs.). Metodologia de pesquisa em jornalismo. Petrópolis: Vozes, 2008.

MEDINA, Cremilda. Narrativas da contemporaneidade: epistemologia do diálogo social. Tríade: comunicação, cultura e mídia, São Paulo, v. 2, n. 4, p. 8-22, dez. 2014.

MEDITSCH, Eduardo. 0 conhecimento do jornalismo. Florianópolis: Ed. UFSC, 1992.

MORAES, Fabiana. 0 nascimento de Joicy: transexualidade, jornalismo e os limites entre repórter e personagem. Porto Alegre: Arquipélago Editorial, 2015.

NEVEU, Erik. "Novos" Jornalismos Investigativos e Ciências Sociais: pensando empréstimos, diferenças e hibridizações. Parágrafo, São Paulo, v. 4, n. 1, p. 29-39, jan./jun. 2016.

QUEIROZ, Nana. Presos que menstruam: a brutal vida das mulheres - tratadas como homens - nas prisões brasileiras. Rio de Janeiro: Record, 2015.

RESENDE, Fernando. 0 jornalismo e a enunciação: perspectivas para um narradorjornalista. Contracampo. Rio de Janeiro, n. 12, p. 85-101, jan./jun. 2005.

RESENDE, Fernando. 0 discurso jornalístico contemporâneo: entre o velamento e a produção das diferenças. Galáxia, São Paulo, n. 14, p. 81-93, dez. 2007.

SILVERSTONE, Roger. Por que estudar a Mídia? São Paulo: Edições Loyola, 2002.

SOUZA, Candice Vidal e. Repórteres e reportagens no jornalismo brasileiro. Rio de Janeiro, Ed. FGV, 2010. 


\title{
Contemporary culture and journalistic
} narratives: the construction of difference in the news stories of Nana Queiroz and Fabiana Moraes

\begin{abstract}
This article reflects upon the treatment and the expressive devices employed by Nana Queiroz, in Presos que menstruam and by Fabiana Moraes, in $O$ nascimento de Joicy, to confer visibility to the anonymous lives they chose to approach. Understanding how such narratives produce meaning in regards to difference, which is shared in the arena of symbolic disputes of contemporary culture is the aim that steers us. In their narratives, Queiroz and Moraes sketch a similar motion: they avoid the coded means of relating alterity, choosing to build entryways through the spaces of invention of the subjects being narrated - inscribing their utterances, experiences and particular ways in a manner that stays away from generalizing conceptions. Supported in the "self" in order to produce the accounts, Queiroz and Moraes, produce reflexive and testimonial rhetoric, writing in a way that is dotted by their subjectivities and that of their characters.
\end{abstract}

\section{Keywords}

Contemporary culture. Journalistic narrative. Alterity. Symbolic disputes. Everyday life.

Recebido em 22/04/2018

Aceito em 29/08/2018 